\title{
What Comprises Clinical Experience in Recognizing Depression?: The Primary Care Clinician's Perspective
}

\author{
Seong-Yi Baik, PhD, Barbara J. Bowers, PhD, Linda Denise Oakley, PhD, and \\ Jeffrey L. Susman, MD
}

Purpose: Depression is a highly prevalent condition in primary care settings. In our previously reported work, we investigated the processes and conditions that influence primary care clinicians' recognition of depression. Three conditions influence the recognition of depression: familiarity with the patient, time available, and clinical experience. This article further describes the role of clinical experience in depression care.

Methods: The grounded theory method was used to guide data collection and analysis. In-depth, inperson interviews were conducted with a purposeful sample of 8 clinicians. All interviews were audiotaped and transcribed.

Results: We identified 3 areas that comprise clinical experience relevant to depression care: (1) knowing one's professional role, (2) knowing oneself, and (3) knowing one's patients. In knowing one's professional role, 4 subdimensions were identified: (1) becoming familiar with illness patterns and clinical skills, (2) learning what works in the real world, (3) understanding what being a doctor is about, and (4) thinking of the whole person. The analysis indicated that clinical experience results from professional and personal growth during interactions with patients. The outcome of this developmental process was the achievement of comfort with depression care, a critical mediating variable that influenced primary care clinicians' recognition of depression.

Conclusions: The developmental process of attaining comfort in managing depression warrants further exploration. Developing interventions to speed this process offers another approach to enhancing care for the management of depression. (J Am Board Fam Med 2008;21:200-210.)

Much has been written about the under-recognition of depression in primary care settings ${ }^{1-7}$ and the associated societal costs. ${ }^{8-15}$ Studies have implicated a range of clinician-related ${ }^{16-21}$ and patient-related ${ }^{22-25}$ factors, as well as factors related to the health care system. ${ }^{26,27}$ Collectively, the findings from these studies suggest that increasing

This article was externally peer reviewed.

Submitted 20 November 2007; revised 25 January 2008; accepted 7 February 2008.

From the College of Nursing (S-YB) and the College of Medicine (JLS), University of Cincinnati, Ohio; Faculty of Health Sciences, Australian Catholic University, Melbourne (BJB); and the School of Nursing, University of Wisconsin, Madison (BJB, LDO).

Funding: University of Cincinnati and the University of Cincinnati College of Nursing.

Prior Presentations: 30th Annual Research Conference of the Midwest Nursing Research Society, March 31-April 3, 2006, Milwaukee, WI; the 8th Annual Qualitative Health Research Conference, April 4-6, 2002, Banff, Alberta, Canada; Academy for Health Services Research and Health Policy, June 10-12, 2001, Atlanta, GA.

Conflict of interest: none.

Corresponding author: Seong-Yi Baik, $\mathrm{PhD}$, University of Cincinnati, Institute for the Study of Health, P.O. Box 670840, Cincinnati, OH 45267-0840 (E-mail: seongyi.baik@uc.edu). clinicians' knowledge about depression by itself does little to increase the likelihood of recognizing depression. ${ }^{28-38}$ A new line of research has identified the importance of the interaction between patients and clinicians in the recognition of depression. ${ }^{21,39-47}$ Our previous research identified 3 interactional processes that primary care providers engage in to determine whether patients are depressed and 3 conditions that may influence the processes: (1) familiarity with the patient, (2) time available, and (3) clinical experience. ${ }^{48}$

Clinical experience generally has been thought to help clinicians make better decisions, especially when a particular skill is involved. ${ }^{49-51}$ Although it may be possible for clinical experience to have a negative impact on clinical decision making ${ }^{52}$ and the dimensions of such a concept warrant further investigation, no study has yet specifically looked at dimensions of clinical experience relevant to depression care. By better understanding the dimensions of clinical experience in depression care, we anticipate new insights into designing quality improvement efforts. This article explores the role of 
clinical experience on the perceived ability of primary care providers to recognize depression in their patients.

\section{Methods}

The Grounded Theory method ${ }^{53-55}$ guided our decisions in conducting this study, from sampling to data collection (including developing subsequent interview questions) and analysis. We used Grounded Theory to generate data that are grounded in the perspective of clinicians (vs researchers), with a focus on eliciting their understanding and experience of a phenomenon (the recognition of depression); how they respond to these understandings and experiences; the conditions that influence their responses; and the consequences of those responses.

\section{Sampling and the Sample}

A Grounded Theory purposeful sampling technique (theoretical sampling) facilitated the constant comparison of cases and helped us identify sources of variation. The final study sample included 8 primary care clinicians: 3 family physicians, 2 general internists, and 3 nurse practitioners. The clinicians were from 8 primary care offices (in small group-practice settings with 3 to 10 clinicians in each office) that are operated by 3 managed care organizations. The years of practice of the participants ranged from 7 to 28 years. Because participation in the study was voluntary, the clinicians who participated may have had a particular interest in depression care. However, none had special advanced training or a certificate in mental health or depression, but a few clinicians had completed some continuing medical education in mental health. We determined theoretical saturation of the conditions when the clinicians repeatedly attributed the same 3 factors to their perceived ability to identify depression in primary care settings: (1) becoming familiar and comfortable with their professional role, (2) learning who they were as clinicians, and (3) becoming familiar with their patients over time. More details about the final sample and sampling for this study are reported in our previous work. $^{48}$

\section{Data Collection}

The University of Wisconsin Institutional Review Board approved the study protocol (\#1999-353) and recruiting letter. After receiving the Institutional Review Board-approved recruiting letter, all clinicians volunteered to participate in this study. Consistent with the Grounded Theory method, ${ }^{53}$ the study was based on in-depth interviews with primary care clinicians, beginning with unstructured, nondirective questions such as, "Tell me about seeing your patients with depression." This type of question allowed the clinicians to inform the researchers about what they saw as relevant to caring for people with depression. Interviews lasted about an hour. As the theme of clinical experience emerged, the follow-up probing became more focused. Table 1 lists examples of interview questions and follow-up probes. We did not ask these questions in the order that they are presented in the table. They were asked naturally, in a way that fit the context of the discussion.

\section{Data Organization and Analysis}

All interviews were audiotaped and transcribed for analysis. A Grounded Theory comparative analysis method with open, axial, and selective coding schemes was used to conceptually categorize and identify relationships among the identified categories (concepts). Specifically, we used open coding to inclusively identify possible dimensions of clinical experience, axial coding to enrich and refine each identified dimension, and selective coding to conceptually organize relationships among the categories (dimensions and subdimensions). To increase our sensitivity to and the reliability of the data analysis, 2 research groups were formed. The initial analysis was done by the research team; this initial analysis was periodically presented to a larger group of qualitative researchers for refinement and feedback. Opening our analysis to other researchers and discussing it among ourselves enabled us to identify assumptions that we might have brought into the analysis and facilitated open exchange about our preconceptions and expectations related to primary care clinicians' practice with depression. For example, family physicians may have a more holistic approach. We resolved differences in the individual team member's interpretations by returning to the data together to be sure that interpretations were grounded in participants' statements and were not researcher speculations. After our analysis of each interview, data analysis matrices were developed to visualize relationships among theoretical categories. These matrices included in- 
Table 1. Examples of Interview Questions Related to Role of Clinical Experience on the Recognition of Depression

Stage of

Interview

Questions

Early Is there any difference between how you recognize depression now and when you were a novice?

What specifically is different between now and when you were a novice?

What do you mean when you say that experience helps you or that you have learned from experience?

Late We have talked with a few clinicians so far, and it seems that experience may be an important condition for how they practice and interact with patients.

Does this make sense to you?

Could you give me an example of how you interact differently with your patients now compared to when you were a novice?

At what point in your practice did you realize that you have changed the way you interact with your patients?

Some clinicians told us that dealing with patients' emotions is not always comfortable, and some mentioned that it got easier as they practiced.

Does this make sense to you?

Could you tell me what the process was for you to become more comfortable with dealing with emotions?

Some clinicians told us that patients do not necessarily disclose their depression and that sometimes they need to dig a little bit to figure out the underlying issues for the patient's depression. They told us that "as you practice" you will know with whom you need to go further and when to do that.

Does this make sense to you?

Could you give me an example of situations when you delved deeper than just the patient's stated issues?

What was it about experience or your practice taught you to do that? How would you advise or teach a novice doctor about how to do that?

dices to supporting quotes and brief but important theoretical memos regarding relationships among the categories that evolved over the course of the interviews.

\section{Results}

From the analysis of in-depth interviews with the 8 primary care clinicians, we identified 3 dimensions of clinical experience that influenced their perceived ability to care for patients with depression: (1) knowing one's professional role (in which 4 subdimensions were identified); (2) knowing oneself; and (3) knowing one's patients. Although not every clinician identified all 3 areas and they varied in terms of the nature of their development, they all indicated that clinical experience does not happen overnight; rather, it is a developmental learning process. The following sections describe the $3 \mathrm{di}-$ mensions and 4 subdimensions of clinical experience as developmental processes; these processes are illustrated in Figure 1.

\section{I-1. Knowing one's professional role: Becoming familiar with illness patterns and clinical skills}

The clinicians, collectively, agreed that their realworld practice offered them a chance to see many cases of illnesses, which increased their ability to see patterns in subtle symptoms and identify the patterns associated with depression. An experienced primary care clinician further elaborated this point:

- "There IS something about. . the experience of bundreds, thousands of patients that you have over time, you start to see patterns of illnesses. And I think the more you're recognizing these patterns, the more you've seen them again and again and again, the easier that gets. And then. . you can go on into deeper levels or nuances of how you do this with your patients." (Family Physician [FP] 2)

Over time, the clinicians became not only familiar with illness patterns but also more comfortable with the skills needed to examine patients. As a result, as they became more comfortable and proficient with clinical skills and could work more quickly than when they were novices. They also were less preoccupied with diagnostic checklists or interview essentials and could pay more attention to interacting with patients. A primary care clinician who practiced for 22 years described the phenomenon:

- "I think as you practice, it's sort of like driving a car. When you first drive a car... it's not very comfortable driving. ... And after you learn how to drive a little bit, then, you can drive in more difficult weather and so on. When you are first practicing, it takes you a long time to evaluate very simple complaints.... But after a while, you feel more comfortable and. . interact with the patient in another way. So while you're doing, for instance, a physical examination, you might be talking to them about something that has nothing to do with the physical examination. . because you're thinking. . . and you're putting that in one part of your brain while the other part is interacting with them on a psychological basis." (FP3) 


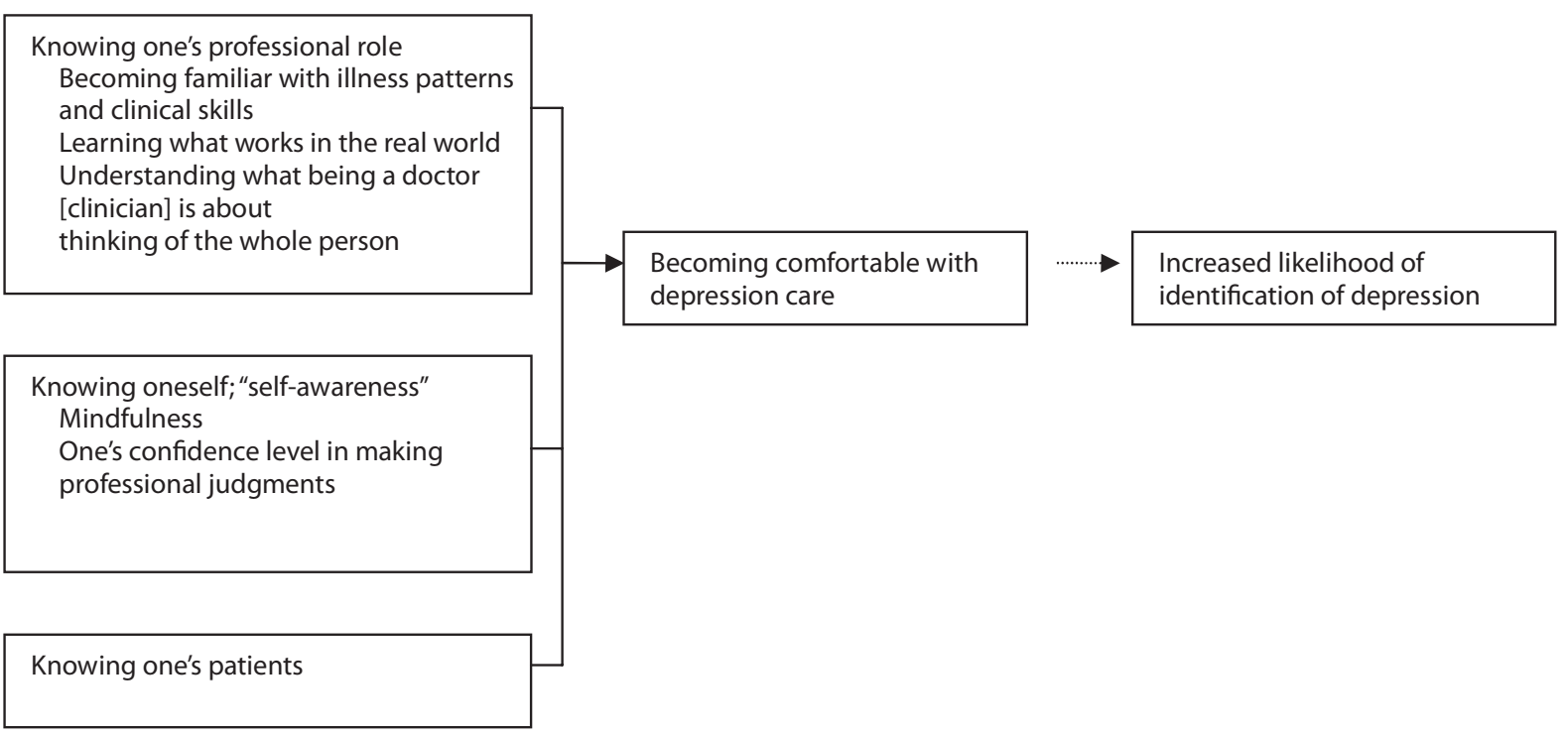

Figure 1. Three processes of clinical experience relevant to the recognition of depression.

\section{I-2. Knowing one's professional role: Learning what works in the real world}

All primary care clinicians in the study explained that, as they practiced, they learned what works best in actual practice. With time, they developed experiential knowledge (in contrast to textbook knowledge). This experiential knowledge affected what clinicians look for to determine whether patients are depressed and how they interact with patients. For clinicians, an implied consequence of having experiential knowledge was that they could finish the work within the allowed time-an important strategy for dealing with the competing demands of primary care practice. This efficiency created space in the clinical encounter to more fully explore potentially psychological issues. Several clinicians described how experiential knowledge helped them recognize depression:

- "I found sleep problems are frequently a good window to finding out about mood problems." (General Internist [GI] 2)

- "I will ask a few screening questions about sleeping and about energy... and once you get that, I'm already into talking about confirming that as the diagnosis and not worrying about their chest pain, and their heart, abdominal pain, and stuff like that, unless they have reason to worry about it." (FP1)

- "Well, if anybody has more than 3 burning complaints, to me that puts up a red flag that there's probably something else going on instead of just a physical ailment. . . is there some other stress thing going on?" (Nurse Practitioner [NP] 3)

Another primary care clinician described how she learned over time what works for her, and, as a consequence, her interactions with patients changed. She learned that letting patients talk about what they have to say, which was a change from her earlier practice, then following up on those issues works better:

- "I used to ask a lot more questions to patients, but now I listen more. At first, I thought I had to go down the list, you know, of hundreds of questions to review systems and so on. And now, I usually depend more on the patients, to saying, How are you doing? And then I'll maybe ask a few specific questions, but I try to spend a lot more time listening than I do talking at first. And I think that's come with practice. That I let the patient tell their own story with a little clarification is better. Rather than me interrupting all the time asking them all these questions." (FP2)

\section{I-3. Knowing one's professional role: Understanding what being a doctor or clinician is about}

Clinicians in the study articulated yet another dimension of experience. As they practiced, they came to better understand who they are as a doctor or health care clinician. This seemed most related to their role of "going into someone's life," being more than someone who treats medical problems and sharing patients' lives over time. They saw their role now, as opposed to before, as someone 
who helps people who are suffering, not just someone who knows illness and treatment. A primary care clinician who has practiced for 14 years talked about how her understanding of who she is as a doctor guides her interactions with patients.

- "I'll try to get a little more than just the main problem, so I get to know the patient as a person, not just as some earache. It helps me because I enjoy my practice more if I know I'm treating people. So if I know the person, I feel like I can do a better job as their doctor. And I don't like just being like a mechanic and treating different body parts.... Knowing who that person is and something about them belps me do a better job caring and being their doctor. Because it's a very personal thing." (FP2)

\section{I-4. Knowing one's professional role: Thinking of the whole person}

Finally, the interviews suggested that, over time, clinicians learned to view the causes of health problems as an inter-relationship among physical and mental aspects. Rather than dichotomizing between mental and physical origins of disease, they began to think in more complex terms and consider both psychological and physical problems simultaneously. This change in their thinking prompted them to delve into underlying mental problems even when an apparent physical health problem was presented. They let the patient talk about "real issues" that were bothersome early in the encounter and searched more fully for underlying problems related to the patient's stated reason for the encounter.

- "Every patient comes with a different combination and it's sort of like solving a puzzle. You bave to try and find out what are the basic causes or underlying problems." (FP2)

- "I doubt that I would ever say that you can separate mental health issues from physical issues any more than you can separate your physical bealth from your mental bealth. If you have anemia and you are exhausted, you become depressed. If you're depressed, then you don't eat, you give yourself anemia." (NP1)

Changes in how clinicians perceived the causes of health problems influenced their approach to depression care. As their understanding of how the mind and body are inextricably related deepened over time and through experience, they became convinced that it is better to try to understand the patient as a whole person rather than adhering to a rote exploration of symptoms or signs ("the checklist") that often compartmentalizes a patient with either physical or mental symptoms. Thinking of the patient as whole person and in the context of his or her life helped the clinicians feel comfortable asking the patient about what is going on; this approach often provided clues to symptoms of depression and facilitated the earlier recognition of depression.

\section{Knowing oneself: "Self-awareness"}

Our analysis indicated a parallel process to professional growth: the attainment of greater self-awareness. Self-awareness is a broad and complex concept with multiple meanings. We identified 2 aspects of clinicians' self-awareness that are directly relevant to the recognition of depression and that have potential consequences for clinicians in their interactions with patients: "mindfulness" and the awareness of one's confidence level in making professional judgments or forming impressions.

Clinicians, when they were mindful of themselves, were more likely to recognize the patient's status, including their physical and emotional appearance. This consequence was an important condition for recognizing depression and is further described in the section on "Recognizing the Person" in our previous article. ${ }^{48}$ Clinicians, when they felt confident in their own judgment, were less likely to use labs and tests to rule out physical causes for an answer to the patient's problem. They could comfortably reject a "ruling out" approach to depression- "I must rule out a long list of medical problems before the diagnosis of depression"which expedited the process of finding an answer and allowed the clinician to present the diagnosis of depression more confidently. The primary care clinicians said that it took time to develop confidence in their professional judgment and that self-evaluation may make a difference in building such confidence. Although not automatic, clinicians reasoned that years of practice offered opportunities to learn from their mistakes and successes. A primary care clinician who practiced for 22 years further described the relationship between confidence and self-evaluation:

- "The issue for a novice practitioner is to realize that they really do have the training and ability to deal with more problems than they think they can deal with. But that confidence is not there. . . Y You have to see that a few times to realize that you can 
deal with it.... And then you also learn because people come back next time, and they are depressed, and you didn't pick it up the first time. But you may pick it up 2 or 3 interactions later, and they'll say oh, I've been depressed for a couple years.... Well eventually, you then learn in the next person who may show those. . signs and symptoms, you know how to pick that up." (FP3)

A primary care clinician with 28 years' experience offered insight on a possible consequence of lacking confidence in one's clinical judgment for ruling out possible explanations. He explained that clinicians who are more confident in their professional judgment engage in less ruling out and fewer labs and tests to confidently diagnose depression:

- "Doctors love to do things like rule out all sorts of stuff, organic stuff, before they say 'it sounds like you're depressed'. It's hard. . for a lot of doctors. . . to just say 'I think you've got depression, I'm not going to do all these blood tests, I think that's what you've got'. Again, that comes from more confidence over the years that your judgment is pretty accurate." (FP1)

\section{Knowing one's patients}

All clinicians talked about how diagnosing depression is highly dependent on knowing their patients, and it often requires familiarity with individuals. Familiarity with each patient was important not only for the clinician to recognize the symptoms of depression in the patient but also for conveying the clinician's recognition to the patient in a way that is palatable to the patient. Clinicians discussed 2 aspects of knowing their patients. The first was that, as a novice, all patients are new and unfamiliar and that it takes time to get to know them. However, they also talked about experience teaching them that familiarity with patients is a key in making the diagnosis of depression. By recognizing a change in a patient's behavior and affect as well as a patient's life context, the diagnosis of depression could be presented. So both the opportunity to acquire personal knowledge of patients and developing the good sense to use that information took time. Before learning how important personal knowledge was, clinicians were much more dependent on textbook definitions of depression, which they believed often led to a failure to recognize depression.

- "One thing that happens over time as you practice is you finally get to a point where you know everybody you see on your schedule each day you've seen before.... I had a full schedule this morning. Wasn't anybody I hadn't seen a number of times before." (GI1)

- "It's easier to say to that person [a patient with whom the clinician is familiar] 'you know, I've really listened to you, you sound really anxious to me, and you're telling me you've had a lot of bad things happen... . I've seen you that often and I'm never really able to find out why you're in such difficulty. What do you think?. . Do you think that you have issues you'd like to talk about with someone in mental health?'” (NP1)

\section{Becoming comfortable with depression care: Outcome of professional and personal growth and increased familiarity with patients}

The clinicians' professional and personal growth over time resulting from many experiences and interactions with patients influenced their conceptualization and consequent behaviors. The clinicians believed that changes in the 3 areas over time made a difference in their comfort dealing with depression care. As clinicians became competent in their clinical skills, clinical judgments, and being "personal" with patients, they became more comfortable with aspects of depression care that require responding to the patient's emotional and mental needs as a whole person, which often necessitates a personal relationship and can be quite time-consuming. The clinicians, collectively, agreed that comfort dealing with depression care is a critical factor for their recognition of depression.

- "It's a matter of if somebody says something, do I know what to tell them? So if they have a psychological issue, can you give them advice?.. When you're first practicing and all a sudden you bave someone in your office who's crying and who's upset, it's harder to bandle than after you've been there before." (FP3)

- "Emotional issues encompass so much of a person's life and it's not something that's real easy to talk about. . they require sometimes an ongoing type of support. . and talking is very time-consuming." (NP2)

Comfort developed over time enabled the clinicians to ask personal questions that they felt, as new clinicians, very uncomfortable asking patients. A primary care clinician who had 28 years of experience talked about how medical students are afraid of asking personal questions. 
- "They don't know how to go into their own lives personally. And they don't feel old enough to do that. And they always talk about prying into people's lives. I said, 'You're getting paid to pry.'" (FP1)

As clinicians learned how important personal knowledge about a patient is for making the diagnosis of depression, some described how experience had taught them to slow down and get to know someone before making a diagnosis. Learning about each patient-in particular, what the patient is willing to accept-led to a much higher level of comfort and, consequently, a greater willingness to suggest the diagnosis. Familiarity with each patient also enabled clinicians to know how to tailor their message to the patient that he or she may be depressed and to tell the patient personally. An experienced clinician who has learned the importance of knowing patients describes his efforts to get to know the patients without necessarily slowing down his practice.

- "I will often, as I'm examining a patient, raise questions that will help me know them a little better. I will ask them about what kind of work they do, how's that going, how their wife's health is, bow their kids are doing. . external things that, you know, are important to everybody." (GI1)

The presented dimensions of clinical experience conceptually describe developmental learning processes that influence the way primary care clinicians identify and respond to patients with depression. As they practice, clinicians become familiar with their own practice and what is expected of them as professionals. With time, they enhance their skills in examining patients, becoming more cognizant of disease presentations, and more comfortable in their professional tasks. This growth enables them to become more efficient, to practice in a less technical (such as textbook knowledge, checking lists of DSM symptoms) and more holistic manner in their approaches, and creates "space" to pay more attention to interactions with the patient. Clinicians learn to recognize that patients are more than a collection of symptoms and to see them as whole people rather than dichotomizing them into physical and mental symptoms. The result of these developmental processes is the achievement of comfort with depression care-a critical mediating variable for the recognition of depression.

\section{Discussion}

Decades of effort to improve clinical decision making have not only generated symptom-based diagnostic criteria intended to facilitate diagnostic reasoning ${ }^{56-58}$ but also have yielded much discussion about how clinicians and clinicians-to-be should be trained and for what they should be trained..$^{59-63}$ Even though clinical experience generally has been thought to assist clinicians in making better decisions and enable them to become more skilled at the care they provide, dimensions of such experience for the recognition of depression have not been explored.

The findings from this study suggest that improving primary care clinicians' detection of depression may require more than teaching them about the symptoms of depression. The presented dimensions of experience suggest that improving primary care clinicians' recognition of depression will require targeting areas of clinical competencies that have not traditionally been targeted, such as clinicians knowing themselves and knowing their patients. Our findings are in line with research studies that address clinical decision making as a 2-way interaction and that aim to discover the variables that influence the interaction to offer strategies for primary care quality improvement. ${ }^{39-47,64}$ Although the patient's influence in such interaction is one factor that affects a clinician's decision making, ${ }^{65}$ our investigation suggests clinicians' professional and personal growth and knowing their patients as another factor. As presented in Figure 1, this study illustrates that clinical experience, as relevant to depression care, is a complex, developmental process and that a clinician's comfort with depression care is a critical mediating variable that grows out of his or her maturation process. Over time and with experience, clinicians learn to better understand themselves and their patients, and this process is closely related to how they take care of patients with depression.

The study has several limitations. First, a sample of 8 clinicians, all from managed care primary care settings, only begins to illuminate the notions that the recognition of depression is mediated through clinicians' comfort. Second, given time limitations, an important theoretical sampling direction was not pursued. That is, we could have explored further the maturation process by employing 2 distinctive groups of clinicians: very new and very 
experienced. Third, even though our findings help us understand how we might craft ways to mitigate novice clinicians' lack of experience and enhance their competencies, what prompts or deters their progression in the 3 areas was not addressed in this study. In addition, the study retrospectively investigated the role of clinical experience when dealing with depression care. Thus, what we found here could very well be clinicians' reconstructed reality that is based on their memory and perception of how they practice and what they did in certain situations. The actual recognition of depression in clinical practice was not investigated; hence, there is no way to link what the clinicians said about their recognition of depression and the actual cases they accurately identified. Finally, our study cannot assess the association of experience with demographics, age, or specific clinical or educational experiences. Nor can we assume such competency is achieved automatically. As Robinson et $\mathrm{al}^{43}$ reported, there may be clinicians who do not make this transition as described in this article; clinicians assume different roles as they mature.

In an effort to improve the quality of mental health care, experts in the field suggest that targeting clinicians-to-be might be a more effective strategy for transforming the care system. ${ }^{66}$ By moving to a competency-based curriculum in medical schools over the past several decades, clinicians are trained in every aspect of patient care rather than in specific tasks or skill acquisition. Yet it seems that there is still less attention given to the interactional aspect of patient care that includes both physicians and patients and focuses on physicians' professionalism, ethics, and communication. ${ }^{59,67-69}$ This poses challenges to clinicians' ability to recognize depression because, as suggested in our study and articulated by Thomas, ${ }^{70}$ "depression is not one thing." How symptoms of depression are manifested and impact one's life differ in each patient. Our study suggests that clinicians who feel comfortable with themselves can pay more attention to the interactional aspect of the clinical encounter and see each patient as a whole person, expediting the recognition process in their patients. In the same vein, as Dowrick ${ }^{71}$ pointed out, giving or not giving a name "depression" may not be a critical public problem, but not recognizing the people who suffer from depression may be.

Our findings suggest several possibilities for future research, intervention, and educational efforts.
Our findings are contrary to the aims of most educational programs for improving primary care clinicians' recognition of depression, which are standardized in nature and thus pay little attention to the interactional aspect in the recognition of depression. ${ }^{72}$ Not all clinicians and clinicians-to-be feel comfortable dealing with the whole person. Nor do they all acknowledge that as their role. Assuming an idealized development of the clinician as healer, a few questions can be directly inferred from our study: what gaps or roadblocks in physicians' practice context impair their maturation process-such as time to get to know patients, continuity of care, the administrative context of mental health care delivery, and/or their familiarity with treatments? What happens if a clinician does not mature in these processes? One future challenge to designing interventions for depression care will be to find the best ways to speed development of clinicians' comfort and to present tools to enhance comfort more quickly, regardless of a clinician's years of practice. Equally challenging is supporting this developmental process with systems that foster continuity, adequate time for encounters, and assuring consultation and mentorship are embedded in the practice environment.

The authors thank Carolyn Dawson, PhD; David A. Kindig, $\mathrm{MD}, \mathrm{PhD}$; Susan Riesch, PhD; and Bonnie Svarstad, PhD, for their discussion in the development of this study, and Junius J. Gonzales, MD, MBA, for his comments on the preparation of the revision.

\section{References}

1. Department of Health and Human Services. Healthy people 2010: Understanding and improving health, 2nd ed. Washington, DC: Government Printing Office; 2000.

2. Regier DA, Narrow WE, Rae DS, Manderscheid RW, Locke BZ, Goodwin FK. The de facto US mental and addictive disorders service system. Epidemiologic catchment area prospective 1-year prevalence rates of disorders and services. Arch Gen Psych 1993;50:85-94.

3. Barrett JE, Barrett JA, Oxman TE, Gerber PD. The prevalence of psychiatric disorders in a primary care practice. Arch Gen Psych 1988;45:1100-6.

4. Katon W. The epidemiology of depression in medical care. Int J Psych Med 1987;17:93-112.

5. Higgins ES. A review of unrecognized mental illness in primary care. Prevalence, natural history, and efforts to change the course. Arch Fam Med 1994;3: 908-17.

6. Borus JF, Howes MJ, Devins NP, Rosenberg R, 
Livingston WW. Primary health care providers' recognition and diagnosis of mental disorders in their patients. Gen Hosp Psych 1988;10:317-21.

7. Perez-Stable EJ, Miranda J, Munoz RF, Ying YW. Depression in medical outpatients. Underrecognition and misdiagnosis. Arch Intern Med 1990;150: 1083-8.

8. US Department of Health and Human Services. Mental health: a report of the Surgeon Generalexecutive summary. Rockville (MD): US Department of Health and Human Services, Substance Abuse and Mental Health Services Administration, Center for Mental Health Services, National Institutes of Health, National Institute of Mental Health; 1999.

9. Ustun TB. The global burden of mental disorders. Am J Public Health 1999;89:1315-8.

10. Coyne JC, Fechner-Bates S, Schwenk TL. Prevalence, nature, and comorbidity of depressive disorders in primary care. Gen Hosp Psych 1994;16:26776.

11. Hays RD, Wells KB, Sherbourne CD, Rogers W, Spritzer K. Functioning and well-being outcomes of patients with depression compared with chronic general medical illnesses. Arch Gen Psych 1995;52:11-9.

12. Wells KB, Sherbourne CD. Functioning and utility for current health of patients with depression or chronic medical conditions in managed, primary care practices. Arch Gen Psych 1999;56:897-904.

13. Hall RC, Wise MG. The clinical and financial burden of mood disorders. Cost and outcome. Psychosomatics 1995;36:S11-8.

14. Henk HJ, Katzelnick DJ, Kobak KA, Greist JH, Jefferson JW. Medical costs attributed to depression among patients with a history of high medical expenses in a health maintenance organization. Arch Gen Psych 1996;53:899-904.

15. Katzelnick DJ, Simon GE, Pearson SD, et al. Randomized trial of a depression management program in high utilizers of medical care. Arch Fam Med 2000;9:345-51.

16. Hirschfeld RM, Keller MB, Panico S, et al. The National Depressive and Manic-Depressive Association consensus statement on the undertreatment of depression. JAMA 1997;277:333-40.

17. Elderkin-Thompson V, Waitzkin H. Differences in clinical communication by gender. J Gen Intern Med 1999;14:112-21.

18. Gerber P, Barrett J, Barrett J, Manheimer E, Whiting R, Smith R. Recognition of depression by internists in primary care. J Gen Intern Med 1989;4:7-13.

19. Main DS, Lutz LJ, Barrett JE, Matthew J, Miller RS. The role of primary care clinician attitudes, beliefs, and training in the diagnosis and treatment of depression. A report from the Ambulatory Sentinel Practice Network Inc. Arch Fam Med 1993;2:106166.

20. Marks JN, Goldberg DP, Hiller VF. Determinants of the ability of general practitioners to detect psychiatric illness. Psychol Med 1979;9:337-53.

21. Roter D, Lipkin M, Korsgaard A. Sex differences in patients' and physicians' communication during primary care medical visits. Med Care 1991;29:108393.

22. Bridges KW, Goldberg DP. Somatic presentation of DSM III psychiatric disorders in primary care. J Psychosom Res 1985;29:563-9.

23. Gerber P, Barrett J, Barrett J, et al. The relationship of presenting physical complaints to depressive symptoms in primary care patients. J Gen Intern Med 1992;7:170-3.

24. Kirmayer LJ, Robbins JM. Patients who somatize in primary care: a longitudinal study of cognitive and social characteristics. Psychol Med 1996;26:937-51.

25. Simon GE, VonKorff M, Piccinelli M, Fullerton C, Ormel J. An international study of the relation between somatic symptoms and depression. N Engl J Med 1999;341:1329-35.

26. Cooper-Patrick L, Crum RM, Ford DE. Characteristics of patients with major depression who received care in general medical and specialty mental health settings. Med Care 1994;32:15-24.

27. Wells KB, Hays RD, Burnam MA, Rogers $W$, Greenfield S, Ware JE. Detection of depressive disorder for patients receiving prepaid or fee-for-service care. Results from the Medical Outcomes Study. JAMA 1989;262:3298-302.

28. Unutzer J, Katon W, Callahan CM, et al. Collaborative care management of late-life depression in the primary care setting: a randomized controlled trial. JAMA 2002;288:2836-45.

29. Boudreau D, Capoccia K, Sullivan S, et al. Collaborative care model to improve outcomes in major depression. Ann Pharmacother 2002;36:585-91.

30. Lin EH, Katon WJ, Simon GE, et al. Achieving guidelines for the treatment of depression in primary care: Is physician education enough? Med Care 1997;35:831-42.

31. Thompson C, Kinmonth AL, Stevens L, et al. Effects of a clinical-practice guideline and practicebased education on detection and outcome of depression in primary care: Hampshire Depression Project randomized controlled trial. Lancet 2000; 355:185-91.

32. Von Korff M, Unutzer J, Katon W, Wells K. Improving care for depression in organized health care systems. J Fam Pract 2001;50:530-1.

33. Frank RG, Huskamp HA, Pincus HA. Aligning incentives in the treatment of depression in primary care with evidence-based practice. Psychiatr Serv 2003;54:682-7.

34. Feldman EL, Jaffe A, Galambos N, Robbins A, Kelly RB, Froom J. Clinical practice guidelines on depression: awareness, attitudes, and content knowledge among family physicians in New York. Arch Fam Med 1998;7:58-62. 
35. Gerrity MS, Cole SA, Dietrich AJ, Barrett JE. Improving recognition and management of depression: Is there a role for physician education? J Fam Pract 1999;48:949-57.

36. Klinkman MS, Coyne JC, Gallo S, Schwenk TL. Can case-finding instruments be used to improve physician detection of depression in primary care? Arch Fam Med 1997;6:567-73.

37. Lin EH, Simon GE, Katzelnick DJ, Pearson SD. Does physician education on depression management improve treatment in primary care? J Gen Intern Med 2001;16:614-19.

38. Tiemens BG, Ormel J, Jenner JA, et al. Training primary-care physicians to recognize, diagnose and manage depression: Does it improve patient outcomes? Psychol Med 1999;29:833-45.

39. Stange KC, Zyzanski SJ, Jaén CR, et al. Illuminating the 'black box'. A description of 4454 patient visits to 138 family physicians. J Fam Pract 1998;46:377-89.

40. Susman JL, Crabtree BF, Essink G. Depression in rural family practice. Easy to recognize, difficult to diagnose. Arch Fam Med 1995;4:427-31.

41. Flocke SA, Miller WL, Crabtree BF. Relationships between physician practice style, patient satisfaction, and attributes of primary care. J Fam Pract 2002; 51:835-40.

42. Miller WL, McDaniel RR, Crabtree BF, Stange KC. Practice jazz: understanding variation in family practices using complexity science. J Fam Pract 2001;50: 872-8.

43. Robinson WD, Priest LA, Susman JL, Rouse J, Crabtree BF. Technician, friend, detective and healer: family physicians' responses to emotional distress. J Fam Pract 2001;50:864-70.

44. Carney PA, Eliassen MS, Wolford GL, Owen M, Badger LW, Dietrich AJ. How physician communication influences recognition of depression in primary care. J Fam Pract 1999;48:958-64.

45. Levinson W, Gorawara-Bhat R, Lamb J. A study of patient clues and physician responses in primary care and surgical settings. JAMA 2000;284:1021-7.

46. Robinson JW, Roter DL. Counseling by primary care physicians of patients who disclose psychosocial problems. J Fam Pract 1999;48:698-705.

47. Meredith LS, Orlando M, Humphrey N, Camp P, Sherbourne CD. Are better ratings of the patientclinician relationship associated with higher quality care for depression? Med Care 2001;39:349-60.

48. Baik S, Bowers BJ, Oakley LD, Susman JL. The recognition of depression: the primary care clinician's perspective. Ann Fam Med 2005;3:31-7.

49. Chang WC, Li TC, Lin CC. The effect of physician experience on costs and clinical outcomes of laparoscopic-assisted vaginal hysterectomy: A multivariate analysis. J Am Assoc Gynecol Laparosc 2003;10:356-9.

50. Manolidis S, Takashima M, Kirby M, Scarlett M. Thyroid surgery: a comparison of outcomes between experts and surgeons in training. Otolaryngol Head Neck Surg 2001;125:30-3.

51. Rollins G. Physician specialty and experience influences asthma outcomes, study finds. Rep Med Guidel Outcomes Res 2001;12:5-7.

52. Choudhry NK, Fletcher RH, Soumerai SB. Systematic review: the relationship between clinical experience and quality of health care. Ann Intern Med 2005;142:260-73.

53. Bowers BJ. Grounded theory. In: Sarter B, ed. Paths to knowledge: innovative research methods for nursing. New York (NY): National League for Nursing; 1989, p. 33-59.

54. Strauss AL. Qualitative analysis for social scientists. Cambridge (UK): Cambridge University Press; 1987.

55. Schatzman L. Dimensional analysis: notes on an alternative approach to the grounding of theory in qualitative research. In: Maines DR, editor. Social organization and social process: essays in honor of Anselm Strauss. New York: Aldine De Gruyter; 1991. p. 303-14.

56. Sox HC Jr. Diagnostic reasoning and probability theory and the interpretation of diagnostic tests. In: Sox HC Jr, ed. Common diagnostic tests: use and interpretation, 2nd ed. Philadelphia (PA): American College of Physicians; 1990, p. 1-33.

57. Crismon ML, Trivedi M, Pigott TA, et al. The Texas Medication Algorithm Project: report of the Texas Consensus Conference Panel on medication treatment of major depressive disorder. J Clin Psych 1999;60:142-56.

58. Pignone M, Ramirez G, Perez Stellato C, Williams JW Jr. Identifying depression in primary care: a literature synthesis of case-finding instruments. Gen Hosp Psych 2002;24:225-37.

59. Carraccio C, Wolfsthal SD, Englander R, Ferentz K, Martin C. Shifting paradigms: from flexner to competencies. Acad Med 2002;77:361-7.

60. Frey K, Edwards F, Altman K, Spahr N, Gorman RS. The 'Collaborative Care' curriculum: an educational model addressing key ACGME core competencies in primary care residency training. Med Educ 2003;37:786-9.

61. Walter A, Bundy C, Dornan T. How should trainees be taught to open a clinical interview? Med Educ 2005;39:492-6.

62. Epstein RM, Dannefer EF, Nofziger AC, et al. Comprehensive assessment of professional competence: the Rochester experiment. Teach Learn Med 2004;16:186-96.

63. Cegala DF, Lenzmeier BS. Physician communication skills training: a review of theoretical backgrounds, objectives and skills. Med Educ 2002;36: 1004-16.

64. Stewart M, Brown JB, Donner A, et al. The impact of patient-centered care on outcomes. J Fam Pract 2000;49:796-804. 
65. Wittink MN, Barg FK, Gallo JJ. Unwritten rules of talking to doctors about depression: integrating qualitative and quantitative methods. Ann Fam Med 2006;4:302-9.

66. Huey L. Problems in behavioral health care: leapfrogging the status quo. Adm Policy Ment Health 2002;29:403-19.

67. Kern DE, Branch WT, Jackson JL, et al. Teaching the psychosocial aspects of care in the clinical setting: practical recommendations. Acad Med 2005;80: $8-20$.

68. Michener L. From turf wars to common ground: the shifting dynamics of medical student education. Ann Fam Med 2003;1:245-6.

69. Block M, National Public Radio. Medical lesson: learning to relate to patients. 27 June 2006. Available at http://www.npr.org/templates/story/story. php? storyId = 5515753. Accessed 17 January 2007.

70. Thomas PR, Annals of Family Medicine. Depression is not one thing. 9 March 2005. Available at http:// www.annfammed.org/cgi/eletters/3/1/31. Accessed 17 January 2008.

71. Dowrick C, Annals of Family Medicine. Is underrecognition of depression really a problem? 14 February 2005. Available at http://www.annfammed. org/cgi/eletters/3/1/31. Accessed 17 January 2008.

72. Schulberg HC, Rollman BL, Annals of Family Medicine. Multiple paths to diagnosing depression. 25 January 2005. Available at http://www.annfammed. org/cgi/eletters/3/1/31. Accessed 17 January 2008. 